\title{
Evaluating Pressure in Deepwater Gas Pipeline for the Prediction of Natural Gas Hydrate Formation
}

\author{
Aijaz Abbasi \\ Department of Mechanical Engineering \\ Universiti Teknologi PETRONAS \\ Bandar Seri Iskandar, Malaysia \\ aijazz.abbasi@gmail.com
}

\author{
Fakhruldin Mohd Hashim \\ Department of Mechanical Engineering \\ Universiti Teknologi PETRONAS \\ Bandar Seri Iskandar, Malaysia \\ fakhruldn_mhashim@utp.edu.my
}

\begin{abstract}
This paper proposes the prediction of hydrate formation pressure in deepwater pipeline with an approach of intelligent optimization. The proposed novel correlation of hydrate formation is using the function of ordinary differential equation. The developed optimization prediction model was founded on the constant coefficients which were examined by a multiple set of experimental data of methane $\left(\mathrm{CH}_{4}\right)$, ethane $\left(\mathrm{C}_{2} \mathrm{H}_{6}\right)$, propane $\left(\mathrm{C}_{3} \mathrm{H}_{8}\right)$, iso-butane $\left(\mathrm{iC}_{4}\right)$, nitrogen $(\mathrm{N})$, Carbon Dioxide $\left(\mathrm{CO}_{2}\right)$ and hydrogen sulfide $\left(\mathrm{H}_{2} \mathrm{~S}\right)$ hydrates. The consequences of this research are highly optimistic for the natural gas production industry.
\end{abstract}

Keywords-intelligent optimization techniques; hydrate formation conditions; natural gases; ordinary differential equation

\section{INTRODUCTION}

A primary challenge for the deepwater hydrocarbon transmission pipeline is the formation of gas hydrate. Thermodynamic properties play an important role in this forming. The natural gas hydrate formation is clogging the deepwater hydrocarbon pipeline on normal thermodynamic conditions [1-3]. A model was developed in [4] to predict the three phases of vapor, liquid and hydrate temperatures from 34 to $60 \mathrm{~F}$, pressure from 65 to $1500 \mathrm{psi}$, and gas gravity 0.552 to 0.9 [4]. An intelligent computational method was used to find the best correlation function for hydrate formation temperature in $[5,6]$ which can be applied to estimate the temperature of gas hydrate formation. An improvement to that model is to predict the temperature and pressure conditions at where hydrate can form in the pipeline. Under this scenario, this research paper suggests intelligent optimization algorithms (GA, PSO and GWO) to be applied with the ordinary differential equation (ODE) model for searching the unknown parameters for the proposed prediction model of hydrate formation pressure. The research objective of this paper is to develop a hydrate formation prediction model for pressure in deepwater pipelines. To achieve this objective, the suggested framework will be incorporated into the development of a correlation model at various gravities and thermodynamic conditions of hydrate formation. The hydrocarbon transmission pipeline is symbolized in a very complex process [7-10], hence making several assumptions of the problem is essential to delimit according to the scope of the study. The study is based on the natural gas hydrate formation in transmission pipeline systems. This refers completely to a network with large diameter pipelines that operate at high pressures. The natural gas transportation process is defined by inherent transient processes, because the problem is assumed as being in steady state. A mathematical model is required to determine the pipeline flow operation for a relatively large amount of flow, since the assumption of the system is to be in steady-state and the flow variables are independent of time. This is describing the flow behavior of natural gas in transmission lines. The governing equations will be described when gas flow, velocity, density, pressure, and temperature are considered as functions of time [11]. The pipeline transportation of natural gas is characterized by a complex process, hence, making demarcate assumptions of the problem is essential to the scope of the study. The modeling of the pipeline resistance is done in such a way that the variability of temperature and pressure is considered for the hydrate formation prediction model.

\section{RESULTS AND DISCUSSION}

Intelligent optimization methods provide predictions of hydrate formation in deepwater pipelines. The unknown variables of the developed correlation model were optimized by an optimization algorithm. The unknown variables were used to enable the correlation-based approach for binary composition of pure water and natural gas hydrate formation thermodynamic conditions. The data will be modeled as a function of the ordinary differential equation (ODE) (1) by applying the optimization algorithm to figure out the relation of thermodynamic properties for hydrate formation pressure. The optimization concept in the development of a hydrate formation prediction model can be expressed as an entity of three main parts: input, process, and output, which were analyzed quantitatively and qualitatively. The optimization method as a mathematical programming formally encompasses several stages [10, 12-15]. This perception is suggesting the idea that the exponential function would be the best function of a prediction model of hydrate formation. The first approach of model equation is a fractional exponent function [1], the model in [4] was an exponential function, and the model in [16] was a polynomial based equation. According to the above observation, the novelty of this model is that the proposed model in (1) is based on an ordinary differential equation (ODE) which is used in the prediction of hydrate formation 
pressure as a thermodynamic property through an intelligent optimization algorithm:

$$
f(P)=\frac{a}{b} e^{b T}+c
$$

where $a, b$ and $c$ are constant coefficient as shown in Table I, $T$ is the flowing temperature, and $P$ is the pressure.

TABLE I. CONSTANT COEFFICIENTS

\begin{tabular}{|c|c|c|c|c|}
\hline \multicolumn{2}{|c|}{ Coefficients } & $a$ & $b$ & $c$ \\
\hline \multirow{3}{*}{$\mathrm{CH}_{4}$} & PSO & 0.413 & 0.096 & -3.50 \\
\hline & GA & 0.387 & 0.097 & -2.16 \\
\hline & GWO & 0.366 & 0.099 & -1 \\
\hline \multirow{3}{*}{$\mathrm{C}_{2} \mathrm{H}_{6}$} & PSO & 0.0511 & 0.152 & 0.161 \\
\hline & GA & 0.044 & 0.16 & 0.271 \\
\hline & GWO & 0.0514 & 0.152 & 0.162 \\
\hline \multirow{3}{*}{$\mathrm{C}_{3} \mathrm{H}_{8}$} & PSO & 0.041 & 0.181 & -0.062 \\
\hline & GA & 0.034 & 0.233 & 0.0241 \\
\hline & GWO & 0.040 & 0.181 & -0.062 \\
\hline \multirow{3}{*}{$\mathrm{iC}_{4}$} & PSO & 0.0176 & 0.206 & 0.031 \\
\hline & GA & 0.017 & 0.197 & 0.025 \\
\hline & GWO & 0.017 & 0.206 & 0.031 \\
\hline \multirow{3}{*}{$\mathrm{CO}_{2}$} & PSO & 0.123 & 0.169 & 0.528 \\
\hline & GA & 0.122 & 0.169 & 0.5311 \\
\hline & GWO & 0.123 & 0.169 & 0.528 \\
\hline \multirow{3}{*}{$\mathbf{N}$} & PSO & 1.9605 & 0.082767 & -8.438 \\
\hline & GA & 1.7372 & 0.088284 & -1.99 \\
\hline & GWO & 1.74 & 0.08821 & -2 \\
\hline \multirow{3}{*}{$\mathrm{H}_{2} \mathrm{~S}$} & PSO & 0.0119 & 0.101 & -0.044 \\
\hline & GA & 0.015 & 0.0887 & -0.152 \\
\hline & GWO & 0.0118 & 0.101 & -0.043 \\
\hline
\end{tabular}

The challenge of using the ODE function is to develop a prediction model with constant coefficients as shown in Table I. The correctness or correlation and analysis of prediction model results were examined by the mean square error equation:

$$
M S E=\frac{1}{n} \sum_{i=1}^{n}\left(x_{\exp }-x_{p r e}\right)^{2}
$$

where, $n$ is total number of data points or numbers of points on $\mathrm{i}, x_{\text {exp }}$ is the existing value, and $x_{p r e}$ is the predicted value.

MSE is applied among the result of model and existing data sets with respect to $i$ iterations [17-22]. The precise computational approach of methanol loss to the vapour phase within hydrate inhibition and right injection rate are calculated in (2) [23]. The neuro-fuzzy method is using (2) to find the growth rate of error [24] and in the Statistical Package for the Social Sciences (SPSS) static model of hydrate formation correlation (2) is also applied to determine its error [25]. The optimum number of hidden neurones is calculated by engaging MSE and regression R-value as an evaluation of ANN-MLP [26]. The relations between temperature, pressure and inhibitor were studied through the experimental data of [27]. These data present significant effects of temperature and pressure on hydrate-formation. The experimental data used give some interesting observations. At a certain temperature, hydrocarbons flow in the pipeline without inhibitors and no hydrate formation, but in the same conditions with lighter specific gravity of gas, hydrate is mostly formed at higher pressures. However, this condition is not always followed by the hydrocarbons. The propane and isobutene mixture of gasses will reduce the hydrate formation pressure notably and nitrogen is acting as an inhibitor. These generate an intelligent optimized result for hydrate formation conditions which are shown in Table II. Hydrate formation prediction conditions for the composition of methane $\left(\mathrm{CH}_{4}\right)$, ethane $\left(\mathrm{C}_{2} \mathrm{H}_{6}\right)$, propane $\left(\mathrm{C}_{3} \mathrm{H}_{8}\right)$, isobutane, nitrogen $(\mathrm{N})$, carbon dioxide $\left(\mathrm{CO}_{2}\right)$ and hydrogen sulfide $\left(\mathrm{H}_{2} \mathrm{~S}\right)$, gases in the deepwater pipeline were predicted on the data of [27] and are given in Figures 1-7. The results show that the developed model provides the best prediction results with minimum error as shown in Table II. It is specified that PSO and GWO give the best prediction results with fewer error points. The overall results of the developed model are validated through the $[1,4,16]$ model equations and their comparison is given in Table II.

This intelligent optimization correlation model is developed on the base of the ODE with 3 constant coefficients which are illustrated in Table I. The best minimum error difference was 2.3 in $\mathrm{CH}_{4}$ (Figure 1). $\mathrm{C}_{2} \mathrm{H}_{6}$ gives 0.054187 with $\mathrm{PSO}$ and GWO (Figure 2), $\mathrm{C}_{3} \mathrm{H}_{8}$ gives 0.0161 in PSO as shown in Figure 3 , isobutene gives 0.010441 with PSO and GWO as shown in Figure 4, $\mathrm{CO}_{2}$ gives 0.093909 with PSO and GWO as shown in Figure 5, N has 2.2619 in PSO as shown in Figure 6, and $\mathrm{H}_{2} \mathrm{~S}$ gives 0.09617 in PSO as shown in Figure 7. The developed model results are addressing the thermodynamic properties of hydrate formation for water and natural gas.

\begin{tabular}{|c|c|c|c|c|c|c|}
\hline \multirow[b]{3}{*}{ Gas } & \multirow[b]{3}{*}{ Algorithm } & \multicolumn{5}{|c|}{ Error } \\
\hline & & \multirow[b]{2}{*}{ Proposed } & \multirow[b]{2}{*}{ [1] } & \multirow[b]{2}{*}{ [4] } & \multicolumn{2}{|c|}{$[16]$} \\
\hline & & & & & $\begin{array}{c}\text { Less than } \\
23 \mathrm{~mol} \\
\text { wt } \%\end{array}$ & \begin{tabular}{|c} 
More than \\
$23 \mathrm{~mol}$ \\
wt $\%$
\end{tabular} \\
\hline \multirow{3}{*}{$\mathrm{CH}_{4}$} & PSO & 2.39 & \multirow{3}{*}{7.74} & \multirow{3}{*}{18.93} & \multirow{3}{*}{12.227} & \multirow{3}{*}{12.259} \\
\hline & GA & 2.55 & & & & \\
\hline & GWO & 2.75 & & & & \\
\hline \multirow{3}{*}{$\mathrm{C}_{2} \mathrm{H}_{6}$} & PSO & 0.054 & \multirow{3}{*}{3.42} & \multirow{3}{*}{8.943} & \multirow{3}{*}{15.007} & \multirow{3}{*}{15.040} \\
\hline & GA & 0.05 & & & & \\
\hline & GWO & 0.054 & & & & \\
\hline \multirow{3}{*}{$\mathbf{C}_{3} \mathbf{H}_{8}$} & PSO & 0.016 & \multirow{3}{*}{4.22} & \multirow{3}{*}{3.443} & \multirow{3}{*}{15.131} & \multirow{3}{*}{15.160} \\
\hline & GA & 0.016 & & & & \\
\hline & GWO & 0.022 & & & & \\
\hline \multirow{3}{*}{$\mathrm{iC}_{4}$} & PSO & 0.010 & \multirow{3}{*}{4.83} & \multirow{3}{*}{1.074} & \multirow{3}{*}{15.155} & \multirow{3}{*}{15.185} \\
\hline & GA & 0.0104 & & & & \\
\hline & GWO & 0.0104 & & & & \\
\hline \multirow{3}{*}{$\mathrm{CO}_{2}$} & PSO & 0.093 & \multirow{3}{*}{7.97} & \multirow{3}{*}{5.849} & \multirow{3}{*}{14.933} & \multirow{3}{*}{14.961} \\
\hline & GA & 0.093 & & & & \\
\hline & GWO & 0.093 & & & & \\
\hline \multirow{3}{*}{$\mathbf{N}$} & PSO & 2.26 & \multirow{3}{*}{19.8} & & & \\
\hline & GA & 2.917 & & 13.21 & 9.515 & 9.542 \\
\hline & GWO & 2.915 & & & & \\
\hline & PSO & 0.096 & & & & \\
\hline $\mathrm{H}_{2} \mathrm{~S}$ & GA & 0.1013 & 13.345 & 23.36 & 15.049 & 15.077 \\
\hline & GWO & 0.096 & & & & \\
\hline
\end{tabular}

TABLE II. ERROR COMPARISON 

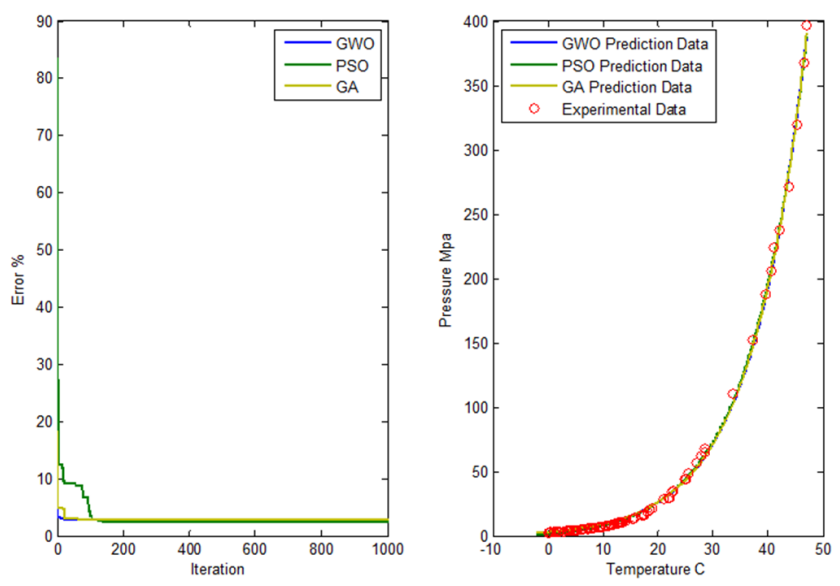

Fig. 1. Methane gas hydrate formation prediction on ODE model
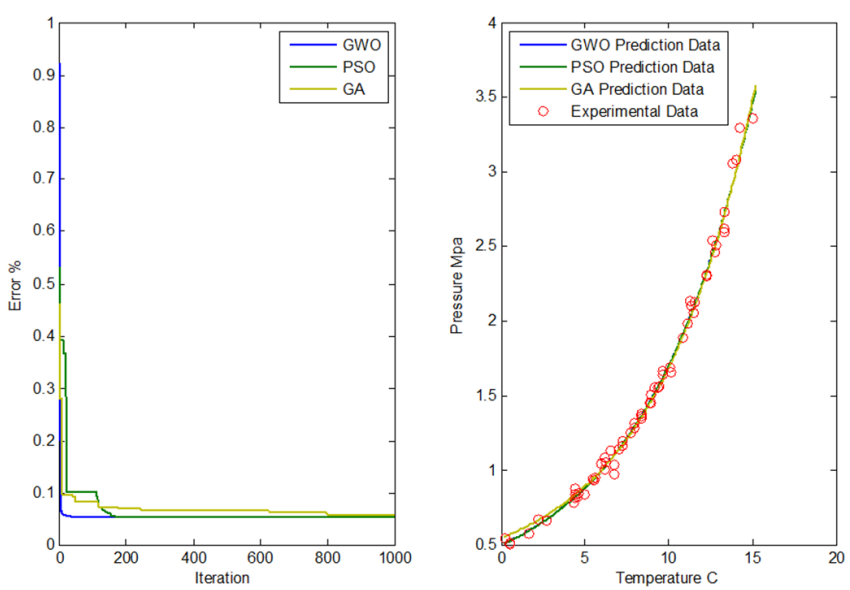

Fig. 2. Ethane gas hydrate formation prediction on ODE model
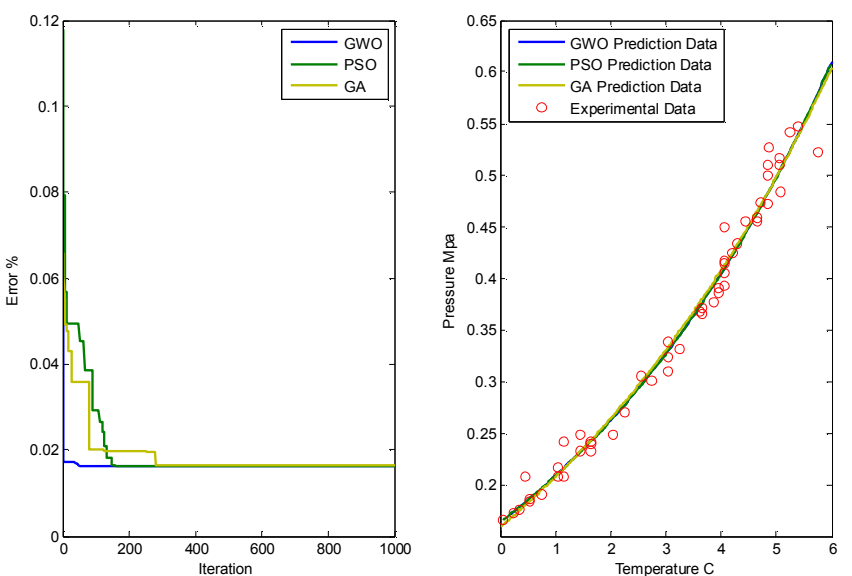

Fig. 3. Propane gas hydrate formation prediction on ODE model
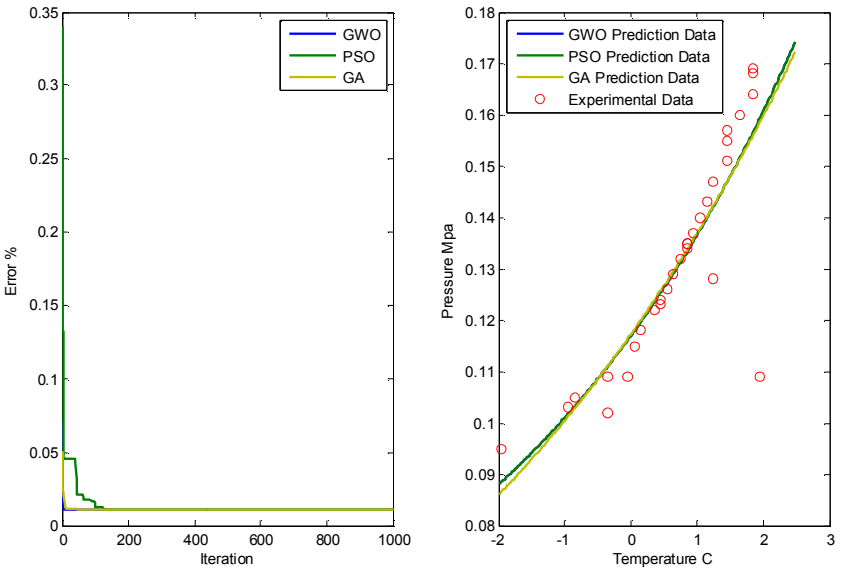

Fig. 4. Iso-butane gas hydrate formation prediction on ODE model
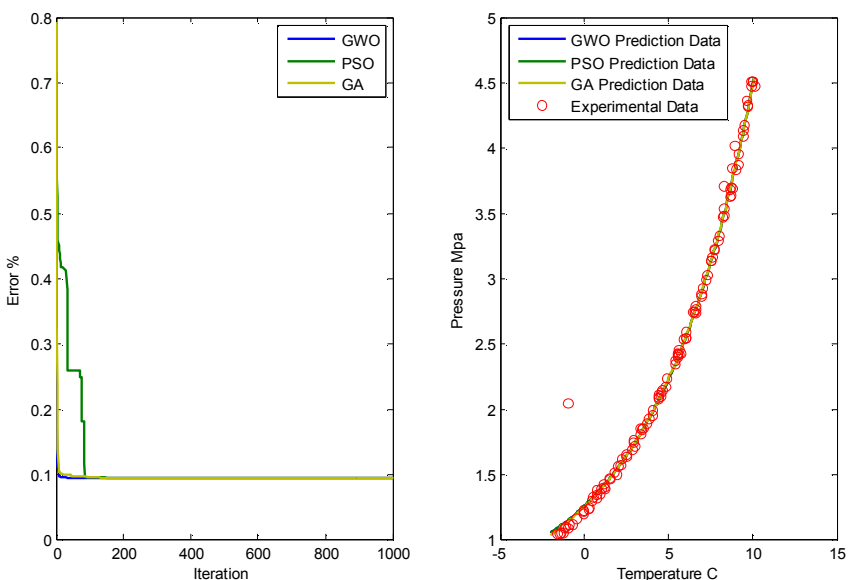

Fig. 5. Carbon dioxide gas hydrate formation prediction on ODE model
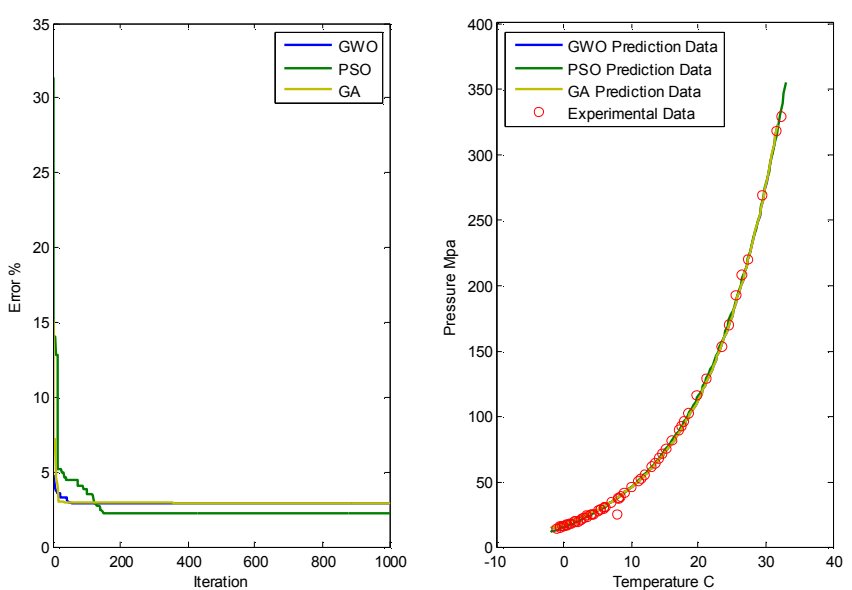

Fig. 6. Nitrogen gas hydrate formation prediction on ODE model 

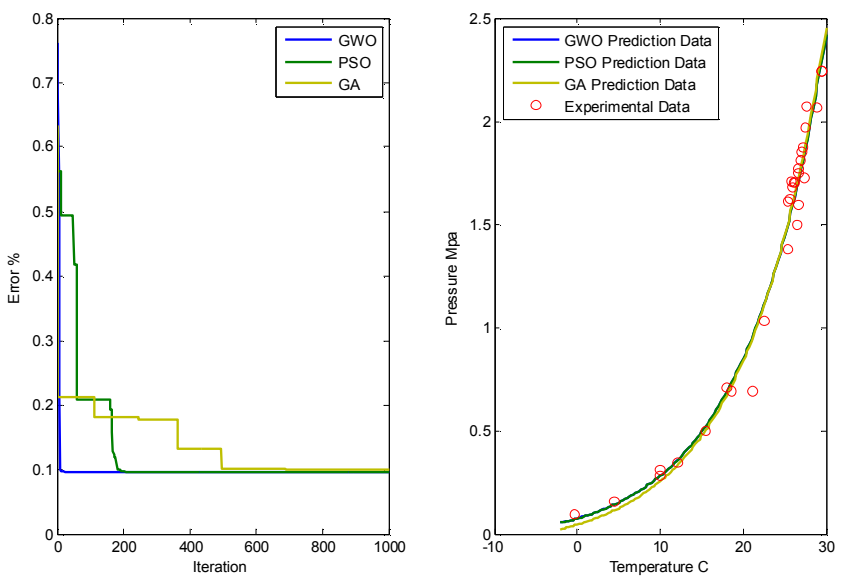

Fig. 7. Hydrogen sulfide gas hydrate formation prediction on ODE model

\section{CONCLUSSION}

The developed model for the prediction of hydrate formation thermodynamic conditions was obtained by ordinary differential equation and optimization algorithms. Results are presenting that GA, PSO and GWO algorithms are effectively discovering the value of constant coefficients. PSO and GWO algorithms are giving overall minimum error. However, there are some limitations in this prediction model which require further research, to enhance its accuracy and functionality. The accuracy of the proposed model can be enhanced by optimizing the phase behavior chart by having more accurate information of natural gas components, water composition and optimize operating conditions of natural gas hydrates formation during production, transportation and processing of natural gas hydrates.

\section{REFERENCES}

[1] E. G. Hammerschmidt, "Formation of gas hydrates in natural gas transmission lines", Industrial \& Engineering Chemistry, Vol. 26, No. 8, pp. 851-855, 1934

[2] J. Carroll, Natural gas hydrate: A guide for engineers, Gulf Professional Publishing, 2003

[3] A. Abbasi, F. M. Hashim, "Hydrate formation prediction model for binary gases of methane+ethane and methane+propane by using optimization algorithm", Petroleum Science and Technology, available at: www.tandfonline.com/doi/abs/10.1080/10916466.2019.1655447, pp. $1-7,2019$

[4] R. G. Kobayashi, K. Y. Song, E. D. Sloan, "Phase behavior of water/hydrocarbon systems", in: Petroleum Engineering Handbook, pp. 25-28, Society of Petroleum Engineers, 1987

[5] A. Abbasi, F. M. Hashim, "A prediction model for the natural gas hydrate formation pressure into transmission line", Petroleum Science and Technology, Vol. 34, No. 9, pp. 824-831, 2016

[6] A. Abbasi, F. M. Hashim, "Development of a hydrate formation prediction model for sub-sea pipeline", Petroleum Science and Technology, Vol. 35, No. 5, pp. 443-450, 2017

[7] D. Mahlke, A. Martin, S. Moritz, "A simulated annealing algorithm for transient optimization in gas networks", Mathematical Methods of Operations Research, Vol. 66, No. 1, pp. 99-115, 2007

[8] E. D. Fatnes, Numerical simulations of the flow and plugging behaviour of hydrate particles, University of Bergen, 2010

[9] W. Duch, J. Korczak, Optimization and global minimization methods suitable for neural networks, Neural Computing Surveys, 1998
[10] Z. Cui, X. Gu, "An improved discrete artificial bee colony algorithm to minimize the makespan on hybrid flow shop problems", Neurocomputing, Vol. 148, pp. 248-259, 2015

[11] R. Z. R. Mercado, C. B. Sanchez, "Optimization problems in natural gas transportation systems: A state-of-the-art review”, Applied Energy, Vol. 147 , pp. 536-555, 2015

[12] C. B. Sanchez, Optimization methods for pipeline transportation of natural gas, University of Bergen, 2010

[13] H. Kang, F. Chen, Y. Li, J. Deng, Z. Yang, "Knot calculation for spline fitting via sparse optimization", Computer-Aided Design, Vol. 58, pp. 179-188, 2015

[14] D. N. Truong, V. T. Bui, "Hybrid PSO-optimized ANFIS-based model to improve dynamic voltage stability", Engineering, Technology \& Applied Science Research, Vol. 9, No. 4, pp. 4384-4388, 2019

[15] K. Soleimani, J. Mazloum, "Designing a GA-based robust controller for load frequency control (LFC)", Engineering, Technology \& Applied Science Research, Vol. 8, No. 2, pp. 2633-2639, 2018

[16] A. Bahadori, H. B. Vuthaluru, "A novel correlation for estimation of hydrate forming condition of natural gases", Journal of Natural Gas Chemistry, Vol. 18, No. 4, pp. 453-457, 2009

[17] M. M. Ghiasi, A. Bahadori, S. Zendehboudi, "Estimation of triethylene glycol (TEG) purity in natural gas dehydration units using fuzzy neural network", Journal of Natural Gas Science and Engineering, Vol. 17, pp. 26-32, 2014

[18] S. Rashid, A. Fayazi, B. Harimi, E. Hamidpour, S. Younesi, "Evolving a robust approach for accurate prediction of methane hydrate formation temperature in the presence of salt inhibitor", Journal of Natural Gas Science and Engineering, Vol. 18, pp. 194-204, 2014

[19] M. Ghavipour, M. Ghavipour, M. Chitsazan, S. H. Najibi, S. S. Ghidary, "Experimental study of natural gas hydrates and a novel use of neural network to predict hydrate formation conditions", Chemical Engineering Research and Design, Vol. 91, No. 2, pp. 264-273, 2013

[20] M. Farzad, H. Tahersima, H. Khaloozadeh, "Predicting the mackey glass chaotic time series using genetic algorithm", SICE-ICASE International Joint Conference, Busan, South Korea, October 18-21, 2006

[21] A. Goshtasby, W. D. Oneill, "Curve fitting by a sum of gaussians", CVGIP: Graphical Models and Image Processing, Vol. 56, No. 4, pp. 281-288, 1994

[22] D. C. Montgomery, Design and analysis of experiments, John Wiley \& Sons, 2008

[23] M. M. Ghiasi, A. Bahadori, S. Zendehboudi, A. Jamili, S. R. Gomari, "Novel methods predict equilibrium vapor methanol content during gas hydrate inhibition", Journal of Natural Gas Science and Engineering, Vol. 15, pp. 69-75, 2013

[24] J. Foroozesh, A. Khosravani, A. Mohsenzadeh, A. H. Mesbahi, "Application of artificial intelligence (AI) in kinetic modeling of methane gas hydrate formation", Journal of the Taiwan Institute of Chemical Engineers, Vol. 45, No. 5, pp. 2258-2264, 2014

[25] E. Khamehchi, E. Shamohammadi, H. Yousefi, "Predicting the hydrate formation temperature by a new correlation and neural network", Gas Processing Journal, Vol. 1, No. 1, pp. 41-50, 2013

[26] M. M. Ghiasi, A. Bahadori, S. Zendehboudi, "Estimation of the water content of natural gas dried by solid calcium chloride dehydrator units", Fuel, Vol. 117, Part A, pp. 33-42, 2014

[27] E. D. Sloan, C. A. Koh, Clathrate Hydrates of Natural Gases, CRC Press, 2007 